\title{
Los primeros ensayos de Ángel Rama: inicios montevideanos de una crítica latinoamericana
}

\section{Ángel Rama's first essays: Montevidean beginnings of a Latin American criticism.}

\section{Resumen}

Los estudios generales sobre el discurso crítico latinoamericano de la segunda mitad del siglo XX colocan al uruguayo Ángel Rama en un lugar central de su construcción y organización. A pesar de los numerosos enfoques ensayados acerca de su obra, repetidas veces su figura es concebida en términos cerrados que lo afilian a la sociología de la cultura, el compromiso político o la militancia latinoamericanista. El análisis de sus primeros artículos, publicados entre 1948 y 1955 en las revistas Clinamen, Marcha, Asir y Entregas de La Licorne, demuestra cómo su praxis crítica se entrecruza inicialmente con elementos propios del campo intelectual uruguayo de mitad de siglo y de qué manera el joven Rama empieza su exploración de la literatura a partir de posiciones, teorías y metodologías muy disímiles a las observadas en sus trabajos clásicos de las décadas posteriores.

Palabras claves

Ángel Rama, Crítica literaria, Historia intelectual, Revistas literarias, Campo intelectual uruguayo.

\begin{abstract}
General studies about Latin American critical discourse of the second half of the 20th Century place the Uruguayan Ángel Rama in a central position of its construction and organization. Despite several approaches outlined about his work, his profile is recurrently conceived by closed ideas which associate him to sociology of culture, political commitment or Latin Americanist activity. The analysis of his firsts articles, published between 1948 and 1955 in journals as Clinamen, Marcha, Asir, Entregas de La Licorne, indicates how his critical praxis is initially intersected with distinctive elements of the Uruguayan intellectual field of the middle of the century and how the young Rama begins his literary exploration through orientations,
\end{abstract}


theories and methodologies which are notoriously divergent from his classic essays of the followings decades.

Keywords

Ángel Rama, Literary Criticism, Intellectual History, Literary Magazines, Uruguayan Intellectual

Field.

Antes de convertirse en paradigma del intelectual comprometido de la década 1960 y mucho antes de que su apellido figurara como una presencia inexcusable en la revisión del pensamiento crítico latinoamericano, Ángel Rama fue uno de los tantos jóvenes que hacia fines de la década de 1940 ingresaron en la escena cultural montevideana a través de un fuerte ímpetu renovador y una acendrada tendencia al debate. Lejos de tratarse de un itinerario individual, su experiencia revistió un sentido colectivo: el crítico participó en el ascenso del grupo de intelectuales que él mismo, décadas después, denominó la "generación crítica". Se trataba de una falange de periodistas, escritores, críticos, artistas y profesores que se vuelcan a revisar la realidad política, económica y cultural uruguaya a través de múltiples intervenciones públicas. Preocupados por la viabilidad de un modelo liberal de país que empezaba a evidenciar sus fisuras e insatisfechos frente a un campo intelectual que encontraban desatento a las nuevas corrientes mundiales, los jóvenes desplegaron una sostenida campaña de revisión de valores y defendieron una producción literaria más ligada al clima de posguerra europeo y norteamericano.

El ámbito preferido para las intervenciones fueron las revistas $\mathrm{y}$ publicaciones periódicas del período. La nave insignia del proceso era el semanario Marcha, fundado por Carlos Quijano hacia 1939 como la expresión de una izquierda cultural, democrática y anti imperialista. A medida que sus páginas se nutrían de nuevas plumas e interactuaban con las inéditas coyunturas históricas que acaecían en el país y en el exterior, la publicación asumió un rol protagónico en la historia cultural ya no solo uruguaya, sino también latinoamericana. Transformada hacia la década de 1960 en tribuna privilegiada del combate de ideas que sobrevino 
CATEDRAL Tomada: Revista de crítica literaria latinoamericana / Journal of Latin American Literary Criticism Los primeros ensayos de Ángel Rama: inicios montevideanos de una crítica latinoamericana.

luego de la Revolución Cubana, Marcha adquirió un aura de mito que trascendió su clausura en 1974 a manos de la dictadura.

Ángel Rama dirigió la sección literaria de Marcha entre los decisivos años de 1958 y 1968, un lapso de tiempo en el que su figura intelectual adquirió una proyección internacional inapelable. Por consiguiente, la imagen de Rama como el crítico literario de Marcha por antonomasia ha coagulado en un lugar común para los estudios latinoamericanos. Aunque la afirmación es parcialmente cierta, la inmersión en el vasto archivo de su discurso crítico revela una formación y praxis intelectual mucho más heterogénea, múltiple y conflictiva, incluso por estos años. Es que gran parte de esta igualación entre el discurso americanista de Marcha y las lecturas que Rama ensaya desde sus páginas literarias ha sido sostenida en principio por el mismo crítico, quien en repetidas ocasiones se ha ocupado por ubicarse a sí mismo en la posición de representante distinguido de Marcha y del equipo intelectual uruguayo, que conjuga el análisis de la "nueva novela latinoamericana" con la militancia a favor de Cuba y los procesos de emancipación en curso por entonces. Dos ejemplos tomados de diferentes textos de su autoría ilustran claramente esta operación. El primero se encuentra en el libro que Rama dedica en 1972 al campo intelectual uruguayo, La generación crítica. Allí, demarca dos orientaciones en la dirección de las páginas literarias de Marcha: por un lado, el proyecto llevado adelante por su antecesor, Emir Rodríguez Monegal, pautado por la exigencia modernizadora, la puesta al día con las innovaciones literarias internacionales y el modelo de la revista Sur; por otro, el dirigido por él mismo, quien se encarga de imprimir a la sección una enfática inquietud política y la necesidad de integrar los textos a la historia, lo social a lo literario, lo nacional a lo latinoamericano. En el marco del libro, atravesado por la idea de un campo intelectual uruguayo que poco a poco se politiza y coloca de forma cada vez más lúcida y comprometida frente a la realidad nacional y mundial, esta operación jerarquiza la propia dirección de Rama en desmedro de la etapa de Monegal. El segundo ejemplo de la igualación se encuentra en el artículo "La lección intelectual de Marcha", escrito en el exilio, en el que Rama afirma: "Cuando don Carlos 
[Quijano] me dijo que esta orientación había permitido que al fin el semanario alcanzara una global coherencia ideológica, me sentí recompensado [...]" ("La lección”21). Este apunte autobiográfico ha terminado por perder su inicial carácter de testimonio para convertirse en una aserción habitual de la bibliografía especializada, en la que suele ser glosada este enunciado en torno a un semanario Marcha que completa su configuración ideológica recién con la llegada de Rama y el debido reconocimiento de Quijano.

En este sentido, vale la pena releer el trabajo de un tercero, Jorge Ruffinelli, también él testigo implicado de la época y la publicación. En su texto "Ángel Rama, Marcha, y la crítica literaria latinoamericana en los 60s", el autor fija desde el título la relación entre intelectual, revista, disciplina y época; luego, pondera a Rama como un cultor de la crítica ideológica, opuesta al inmanentismo de Rodríguez Monegal, y afilia sus textos a una práctica comprometida con la búsqueda de la integración latinoamericana. Aunque irrefutable, la observación es limitada para pensar la conformación del discurso crítico de Rama, que se halla cruzado por inflexiones, orientaciones y experiencias muchos más complejas que los contempladas en la ecuación Marcha-latinoamericanismo-Cuba-compromiso intelectual-nueva novela.

Por lo tanto, la propuesta del siguiente trabajo es revisar un segmento de la producción del crítico uruguayo, quien ha sido señalado como el insigne religador de obras, autores y proyectos latinoamericanos (Zanetti), el gran tejedor de redes de la familia intelectual de la década de 1960 (Gilman, "Enredos y desenredos") o el lector atento que, por compromiso, capacidad y lucidez, llega a ser el hermeneuta de la hora (Rocca, Ángel Rama).

Lejos de esta perspectiva continental y totalizadora de su trayectoria, a continuación se recorta un corpus que remite a otra instancia de su pensamiento; una más temprana, primigenia y juvenil, menos proclive a la polémica en escala épica y más atenta a las letras y la filosofía universal. Son textos tomados de revistas universitarias o de escasa circulación, con públicos reducidos y una interpelación más limitada, a través de los cuales el joven Ángel Rama da sus primeros pasos 
CATEdRal Tomada: Revista de crítica literaria latinoamericana / Journal of Latin American Literary Criticism Los primeros ensayos de Ángel Rama: inicios montevideanos de una crítica latinoamericana.

como crítico en la escena uruguaya y empieza construir su voz enunciadora. También se abordan sus primeros trabajos en Marcha, publicados durante los seis meses en los que dirigió, junto a Manuel Flores Mora, las páginas literarias del semanario. Estos trabajos críticos, desarrollados en una etapa de formación juvenil, contrastan con la praxis del intelectual adulto, combativo, politizado y latinoamericanista y demuestran una gran diferencia en sus objetos de estudios, entonaciones discursivas, objetivos programáticos y metodologías de lectura. El análisis de estos artículos, publicados entre 1948 y 1955, permite de esta manera no solo identificar rupturas y continuidades de su trayectoria crítica que no han sido suficientemente profundizadas, sino también evadir lugares comunes de la bibliografía más clásica y avanzar a la vez sobre puntos ciegos en la recuperación orgánica de su obra.

\section{Clinamen: una primera aventura estudiantil}

A los veintiún años, Ángel Rama comienza a estudiar literatura en la Facultad de Humanidades y Ciencias, donde conoce y traba amistad con quienes luego integran junto a él las primeras promociones de la generación crítica. Además, toma cursos con José Bergamín, uno de los intelectuales españoles que se exilian a Montevideo y quien despierta una notable admiración en algunos círculos uruguayos. Hacia 1947, se funda Clinamen, una de las tantas revistas literarias surgidas en la época, cuyo consejo de redacción está formado por Víctor Bacchetta, Manuel Claps, Ida Vitale y Ángel Rama, quien también es designado su "redactor responsable". La publicación tiene una vida corta: solo cinco ejemplares logran salir a la calle durante dos años. El repentino desenlace es explicado por Pablo Rocca en uno de sus imprescindibles trabajos sobre las revistas rioplatenses: como otras iniciativas similares, Clinamen no logra armar una amplia y creciente red de lectores, suscriptores y auspiciantes que sea capaz de sostener el diálogo vivo entre autores y público ("Las revistas”). 
Una primera muestra de los aspectos inesperados en la praxis del joven Rama que se halla en las páginas de Clinamen es el tipo de trabajo que firma en el número inaugural de la revista, publicado en abril de 1947. El índice de la publicación indica que el único texto de crítica literaria es escrito por Idea Villariño. El resto del material editado se compone de reseñas de libros nacionales y extranjeros, un breve ensayo de Bachetta sobre Husserl, cuatro sonetos de Ida Vitale y fragmentos de un trabajo de Simmel. Rama aparece aquí únicamente como responsable de una traducción del cuento "Cristina”, del escritor Julien Green, cuya versión firma con sus iniciales A.A.R. Es decir, su primera incursión en el campo intelectual uruguayo no es como crítico, sino como traductor. Para la época, la tarea es habitual y responde a las exigencias de la puesta al día con el mundo contemporáneo que los jóvenes propugnan. ${ }^{1} \mathrm{Y}$ en el caso particular de Rama, la operación se corresponde con su conocimiento del idioma francés, gracias al cual se desempeña como traductor de la agencia France-Presse entre 1945 y 1947 (Blixen y Barros-Lémez 13) y con la atención permanente puesta en los nuevos rumbos del pensamiento europeo. A pesar de eso, esta faceta de su obra, que reaparece en distintos momentos durante las siguientes décadas (en 1974 traduce en Venezuela a Roland Barthes, por ejemplo), ha pasado bastante desapercibida y merece una mayor atención crítica.

En el segundo número de Clinamen, el artículo que Rama publica sobre el Martín Fierro demuestra de forma contundente hasta qué punto, en los inicios, su discurso crítico se constituye sobre líneas teóricas y motivaciones intelectuales ajenas a la inquisición ideológica que estructura su interpretación de la poesía gauchesca de uno de sus libros clásicos de la década de 1970, Los gauchipolíticos rioplatenses. En el texto de mediados de la década de 1940, la lectura sobre la obra de José Hernández se inscribe dentro de los estudios estilísticos de la poesía culta

${ }^{1}$ La traducción como tarea programática de la generación crítica es aún más importante en la praxis de Emir Rodríguez Monegal, hasta el punto que Pablo Rocca llega a resumir la orientación de su paso por Marcha en los siguientes términos: "Algo que podría denominarse una política de traducción de la novedad metropolitana, constituyó el sello propio de su etapa en la página literaria del semanario" (Ángel Rama, 132). 
hispanoamericana y se reconstruye a través de un sistema de citas que privilegia los aportes de autores españoles (Unamuno, Menéndez y Pelayo y luego Azorín), a quienes se identifica como los responsables de elevar el texto argentino a la condición de obra literaria. No hay una mayor incidencia en el artículo de otras perspectivas en torno al poema, sino un insistente contraste con lo que Rama llama "la entusiasta e ingenua aceptación popular". Sobre este distingo entre la exégesis culta de los españoles y la recepción del gran público avanza la principal argumentación del artículo. A partir del análisis del juego de voces narradoras, que se desplaza desde la reconstrucción ficcional de un tono gaucho hacia la omnisciencia del escritor culto que refiere la escena final de la Ida, se postula que la propuesta central del texto de Hernández es trascender el caso particular y proyectarse como una representación arquetípica del antiguo habitante de las pampas argentinas: "El naipe individual de Martín Fierro ya no interesa. Importa la raza y la raza, en el criterio de Hernández, no puede morir” (“La composición” 42).

Sus otros cinco textos publicados en Clinamen agregan nuevos matices. El primero de ellos se encuentra en el mismo ejemplar en que aparece su artículo sobre Martín Fierro. Es una nota firmada a través de uno de sus seudónimos, Antonio Facal, sobre el libro La historia y la novela, escrito por su hermano mayor, Carlos Rama. En la reseña, se coloca al autor en la confluencia de dos legados (el de Unamuno y el de Caillois) y se lo afilia a la gran tradición humanista occidental. Ángel coincide con Carlos en la ponderación de la disciplina histórica y el género novelesco como dos grandes aportes complementarios para el estudio integral del hombre en relación con su entorno ("La historia" 63).

Además de la traducción anteriormente observada, la pregnancia francófila del campo intelectual uruguayo de mitad de siglo se manifiesta en el joven Rama en otro texto que publica en Clinamen sobre el volumen de Karl Vossler, La Fontaine y sus fábulas. Allí, el crítico valora el trabajo del gran referente de la estilística alemana a través de su comparación con otros juicios alrededor de La Fontaine, como los de Saint Beuve, Boileau, Frague, Hugo, Bailly, Nahin, Boillot o Gohin, lo que indica tanto la asidua frecuentación de la biblioteca clásica francesa, 
como la marcada atención hacia sus trabajos más contemporáneos. Rama escribe como si fuera un crítico francés: cita profusamente fragmentos y títulos en idioma original y destaca el libro de Vossler a partir de una sugestiva observación: La Fontaine es un escritor "destinado exclusivamente al lector francés, cuyos cuyas bellezas y valores son asequibles con mayor hondura por sus compatriotas" ("La Fontaine" 51). En consecuencia, la correcta y lúcida interpretación de su obra por parte de un alemán, en palabras de un uruguayo, es índice de su altísima capacidad de lectura. El espíritu de síntesis de Vossler, atento a cuestiones formales y biográficas, termina por colocar su ensayo como un auténtico "modelo de crítica literaria".

La inclinación francesa de la cultura uruguaya de la primera mitad de siglo permite una temprana y significativa recepción de las obras de Sartre, Camus y las ideas existencialistas, de las cuales Clinamen se hace eco a través de las diferentes notas y reseñas. En el número tres aparece la traducción de Miguel Ángel Virasoro de un fragmento de El Ser y la Nada y, en el último volumen, Rodríguez Monegal analiza la obra literaria de Jean-Paul Sartre. Pero la intervención de Ángel Rama en torno al existencialismo francés y el magisterio de su máximo representante se destaca frente a esos textos por la manera que elige para apropiarse de él. No encontramos en Clinamen artículos, ensayos o reseñas suyas dedicadas al estudio, el debate o la difusión existencialista, sino una pieza narrativa; "El preso", que abreva notablemente en la estética, los temas y las ideas del pensamiento francés en boga. El cuento se constituye como el primer trabajo literario publicado por Rama, más allá de haber permanecido al margen de la crítica que ha revisado su obra ficcional (Moraña, Barros-Lémez). ${ }^{2}$

El texto se presenta en parte como una reescritura de la pieza narrativa "Le mur", de Jean Paul Sartre, tal cual lo ha señalado oportunamente Pablo Rocca (El

\footnotetext{
${ }^{2}$ Cabe destacar que la atención puesta por la investigadora brasileña Roseli Barros Cunha hacia la narrativa de Rama no descuida este texto. El mismo aparece incluido en la completa cronología que acompaña su traducción al portugués de Tierra sin mapa, el texto del crítico uruguayo sobre Galicia, la región natal de su madre (Rama Terra).
} 
CATEDRAL Tomada: Revista de crítica literaria latinoamericana / Journal of Latin American Literary Criticism Los primeros ensayos de Ángel Rama: inicios montevideanos de una crítica latinoamericana.

45 95). En efecto, el texto narra los últimos momentos de un intelectual comprometido que aguarda en la cárcel el momento de su ejecución. Hasta ahí, la semejanza con el cuento de Sartre es evidente. Pero donde aparecen las diferencias, se evidencia el sentido crítico de la operación textual. "El preso", lejos de ser una traducción llana que solo borra al autor francés, es una apropiación original que busca representar posturas y dilemas de los jóvenes montevideanos que componen la generación crítica. Así, a partir del esquema argumental dado por el cuento de Sartre, Rama modifica ciertos elementos de la trama que iluminan su propia percepción del desafío existencialista. La Guerra Civil española ya no es el referente histórico donde se enmarca el relato. El narrador señala con precisión que la coyuntura es otra. Según se lee, la acción transcurre "en ese pequeño país de la América del Sur, sin tradición, sin cultura, sin recuerdo" ("El preso" 12), tras el intento frustrado de tomar el cuartel general del ejército. A la vez, el protagonista deja de ser un anarquista que se debate sobre el sentido de la lucha y la posibilidad de la delación y pasa a ser un profesor universitario que indaga sobre las consecuencias de su decisión de abandonar el círculo letrado para intervenir en la lucha armada. Encerrado en la prisión, el personaje lamenta tener inconcluso, entre otros trabajos, un ensayo sobre la biblioteca de Montaigne y el gran libro de su vida, una inquisición sobre los grandes problemas de su tiempo y la posibilidad de superar los obstáculos al desarrollo humano impuestos por la sociedad y la historia. La cercanía de la muerte crispa las contradicciones del profesor, quien piensa en sus jóvenes estudiantes y afirma: "No, él no estaba hecho para ser maestro de aquella juventud. No podía seguir viviendo en el plano aséptico de los temas literarios. Rehuir aquellos rostros ansiosos, hablarles del estilo de Fray Luis cuando reclamaban una palabra para la vida" (12). Sin embargo, cuando finalmente es llevado al pelotón, su último pensamiento se vuelca sobre las palabras del poeta español Antonio Machado acerca de la finitud de la vida y la eternidad del arte.

De esta manera, muchos años antes de la Revolución Cubana, los planteos de Sartre sobre el compromiso de los intelectuales permean el discurso de Rama, quien se vuelca a discutir la figura del profesor como el maestro de la juventud y la 
actualidad del humanismo idealista, dos tópicos centrales de la cultura uruguaya impuestos por José Rodó en Ariel, el ensayo de principios de siglo XX que más hondo cala en el ámbito nacional y aún continental. El cuento denuncia la falta de sentido de una docencia preocupada por los temas más elevados del pensamiento y la literatura universal, a la vez que explora los rasgos más problemáticos de una subjetividad que pasa de la cátedra a la acción directa. La vinculación entre la biografía de ese profesor y la mirada de Rama hacia sí mismo, sus congéneres y sus maestros implica tanto una toma de posición frente al existencialismo como un estado de la cuestión en las tierras uruguayas. El joven crítico abjura a través del texto del tradicional magisterio arielista y apuesta a la asunción del compromiso político hasta las últimas consecuencias, pero en vez de manifestarse a través de un ensayo que avale sus enunciados con la propia firma, lo hace por medio de un cuento que sumerge las críticas y proposiciones en el juego de voces narradoras. La lección de Sartre se adopta solamente bajo el artificio de la ficción. Si bien una parte central del enjuiciamiento hacia sus mayores avanza por el camino de la literatura inspirada en el existencialismo francés, el involucramiento concreto con las luchas políticas se difiere y proyecta hacia una situación revolucionaria futura. Por el momento, los propios esfuerzos como estudiante, crítico y escritor, se orientan hacia el mismo mundo de las letras que habita el protagonista del cuento, incluso en su doble filiación, la española y la francesa. Deberá pasar todavía más de una década hasta que Rama se encuentre, él también, con su propio destino de intelectual sudamericano.

Para concluir con la revisión de Clinamen, resta observar que en sus páginas se lee otra inflexión que caracteriza la praxis del crítico desde sus inicios: la tendencia hacia el debate frontal y el juicio polémico. En el mismo número donde se publica "El preso", por ejemplo, Rama firma con su seudónimo Antonio Facal la nota "Temporada de Teatro Nacional", en la que arremete sin contemplaciones contra las obras exhibidas en Uruguay durante 1947. El horizonte dramático del país aparece representado en un estado paupérrimo que irrita al autor y lo lleva a plantearse incluso el sentido de una nota crítica, a la que renuncia para limitarse a 
CATEDRAL Tomada: Revista de crítica literaria latinoamericana / Journal of Latin American Literary Criticism Los primeros ensayos de Ángel Rama: inicios montevideanos de una crítica latinoamericana.

revisar algunos elementos que justifican su parecer al respecto. Un tono similar atraviesa el artículo "Generación va, generación viene”, que aparece en el último número de Clinamen y que se configura como un texto de intervención en el debate acerca del surgimiento de una nueva generación de escritores, artistas e intelectuales en el Uruguay de mediados de la década de 1940. Participan de la discusión diversas publicaciones (Escritura, Marcha, Cabalgata) y diferentes autores (Carlos Maggi, José Pedro Díaz, Carlos Ramela, Emir Rodríguez Monegal, Manuel Flores Mora). En este contexto, el trabajo de Rama apunta la esterilidad de la polémica y critica el uso falaz de la noción de "generación". Apelando a referentes teóricos como José Ortega y Gasset, Julius Petersen y, principalmente, Ernst Curtius, el joven crítico señala que el uso del concepto oculta, en realidad, una mirada limitada sobre la historia literaria uruguaya y un análisis superficial de las nuevas creaciones. Rama propone suplantar el debate sobre la nueva generación por una tarea común para todos los involucrados. Su programa consiste en cuatro tareas centrales: estructurar la tradición cosmopolita y universal desde las particularidades de la cultura uruguaya, revisar y ordenar el pasado literario nacional, renovar la producción artística y el discurso crítico y construir un sistema de publicación y circulación de textos que pueda romper por fin con la inercia de las generaciones precedentes y con la fragilidad de las iniciativas juveniles.

El último punto demuestra el nivel de conciencia adquirido sobre la débil sustentabilidad de las revistas de la época. El fin apresurado de Clinamen tras este quinto número termina por confirmar el pronóstico ensayado.

\section{El primer paso por Marcha: en busca de una voz y de un modelo}

En 1948, Rama toma cursos en el Instituto de Profesores Artigas y hacia el año siguiente inicia un extenso período de trabajo en la Biblioteca Nacional, decisivo para su formación intelectual y también para su inserción institucional. 
Desde ese lugar se pone al día con las últimas adquisiciones bibliográficas, dirige colecciones, prologa libros y organiza ediciones, salas, archivos y exposiciones. A la par, Rama asciende súbitamente a la primera plana de la escena cultural uruguaya: con veintitrés años, asume junto a Manuel Flores Mora la dirección de las páginas literarias del semanario Marcha. Esta novel incursión es breve (dura apenas ocho meses) y se distingue de la segunda y definitiva experiencia al frente de la sección desde finales de la década de 1950. En esta oportunidad, los textos que escribe en la publicación demuestran difícilmente la llamada "integración" de la parte política y la cultural del semanario. Más bien, lo que se observa en sus textos es una tónica similar a la impuesta por el crítico literario más célebre de ese momento, Emir Rodríguez Monegal: detención y urgencia por la novedad cosmopolita, inspección aguda de la producción nacional, polémica con medios e instituciones que impiden la debida modernización. En todo caso, hay una evidente retracción frente a Borges, el grupo Sur y la literatura inglesa y estadounidense, los objetos privilegiados de la lectura de Monegal, que son suplantados por autores y movimientos internacionales ligados a la propia formación de Rama y las orientaciones más clásicas de la cultura uruguaya. Son los mismos que se han destacado como centrales ya en su período en Clinamen: Francia y España se refrendan aquí como las dos matrices nucleares que proveen al joven crítico de modelos intelectuales y horizontes literarios. ${ }^{3}$

Entre los primeros, destaca el magisterio francés. A partir de la visita de Albert Camus a Montevideo en 1949, Rama escribe su primera nota breve en Marcha sobre las aclamadas conferencias del escritor en la capital uruguaya. El joven crítico traza sobre el autor un perfil de caracteres modélicos, que va más allá de una "profesión de fe" (Rocca 35 años 88). En el artículo, Camus es destacado como intelectual, por su "personalidad vigorosa", que interviene en los debates más

3 Oportunamente, Pablo Rocca discute un rígido pero muy usual esquema que piensa las orientaciones críticas de Monegal y Rama como la contraposición entre el tecnócrata anglófilo y el militante latinoamericano. Ante la simplificación, Rocca refuta a través del archivo: "Al contrario, entre 1947 y 1960, Rama se dedica a la literatura española y francesa con mayor interés que a la hispanoamericana, con excepción de lo uruguayo" (Rocca, Ángel Rama 138). 
CATEDRAL TOMADA: Revista de crítica literaria latinoamericana / Journal of Latin American Literary Criticism Los primeros ensayos de Ángel Rama: inicios montevideanos de una crítica latinoamericana.

urgentes de su tiempo sin ningún tipo de dependencia a facciones culturales o grupos políticos; como escritor, por su creación literaria, que representa estéticamente al hombre contemporáneo en plena situación de combate con sus dilemas dudas, miedos y frustraciones; como existencialista, por la inflexión sincrética que Camus imprime a su pensamiento, alejado de la orientación de Sartre, que Rama encuentra más analítica, abstracta y proclive a fragmentar la totalidad de la experiencia humana. Tal como se lee, sobresale en el texto el sesgo humanista del propio crítico, quien concluye su artículo con la siguiente frase: “[...] La actitud de un escritor como Camus significa una nueva esperanza para una literatura vinculada auténticamente al hombre, y la hacemos nuestra por ello, y por representar el camino más cierto para las letras de nuestro país" (“Albert Camus" $15)$.

En torno a los intelectuales españoles, la atención del joven crítico también demuestra una fidelidad de larga data, motivada por el origen peninsular de sus padres inmigrantes, sus propios estudios sobre literatura hispánica y el impacto que la Guerra Civil tiene en los círculos letrados y políticos de América del Sur que siguen de cerca el conflicto. De esta manera, Rama no solamente aprovecha una lectura pública de Rafael Alberti para reseñar el evento y tomar notas de las nuevas inflexiones de su poética ("Rafael Alberti”), sino que se hace lugar entre las páginas literarias de Marcha para homenajear al escritor y dibujante gallego Castelao ("Castelao"), comentar una publicación de textos de Miguel Hernández ("Inéditos") e incluso discutir la última publicación de las obras completas de Antonio Machado por parte de una España franquista que recupera su obra a fuerza de recortar en ella la militancia y entonación republicana (“Obras completas"). Un breve texto que explícita los intereses y desintereses de Rama en la observación de la realidad cultural uruguaya es el balance de conferencias del año 1949: la visita de Borges, la presentación de El Aleph y su defensa de la literatura fantástica son registradas sin ningún tipo de comentario; la charla de Sábato sobre el panorama de la literatura mundial se considera "fallida" y la exposición de Veríssimo se cataloga como poco original. En cambio, la llegada de Camus y Derek Traversi y su 
encuentro con el público uruguayo es celebrado como un evento brillante, mientras que el ciclo de conferencias del español José Bergamín sobre literatura pastoril, novela caballeresca y picaresca, el legado de Cervantes y el romanticismo europeo constituye "el acontecimiento cultural más importante del año" ("Algunas conferencias" 5). ${ }^{4}$

Rama vuelve a escribir sobre los protagonistas de la escena intelectual francesa unos meses más tarde, al evaluar la relación entre los escritores y la política partidaria. La aptitud del cronista vuelve a ser la del experto: los títulos de obras y publicaciones están en idioma original, como en Clinamen, y la revisión de movimientos y agrupaciones develan una mirada actualizada en extremo. Rama organiza a los escritores según su filiación ideológica y arma un esquema que incluye los nombres de Benda, Malraux, Mauriac, Eluárd y Aragón, para luego detenerse en lo que se considera la iniciativa más promisoria en el sector de las izquierdas francesas: el encabezado por Sartre, Rousset y Rosenthal, quienes fundan el "Rassemblement Démocratique et Révolutionnaire". La importancia para el crítico es la posibilidad de un movimiento político que torne posible una alternativa marxista no soviética, una suerte de "tercerismo" solidario con el defendido por la dirección de Marcha. Pero aún en esta nota dominada por la cuestión política predomina un enaltecimiento de la labor literaria que termina por reducir el aspecto ideológico del tema. Si bien la agrupación de Sartre sirve de referente para el panorama mundial de las izquierdas democráticas, el ejemplo de los franceses resalta principalmente por la coherencia con que éstos encarnan el modelo de escritor humanista defendido y expresado por Rama. Los intelectuales son descriptos como "hombres que gozan de prerrogativas superiores a las del común de los mortales que por lo tanto entrañan mayores y más graves responsabilidades" ("Los escritores franceses" 15). El exceso retórico indica que la idealización arielista continúa operando en su pensamiento, al enaltecer con

\footnotetext{
${ }^{4}$ Cfr. con el señalamiento del mismo Rama en un célebre artículo de 1960, en el que considera la Revolución Cubana como el evento cultural del año (“La construcción”).
} 
elocuencia la función integradora y humanista del arte y la literatura, aún en desmedro de la política, la sociología o la militancia.

La francofilia y la entronización del hombre de letras atraviesan otros artículos. Por ejemplo, el que le dedica a André Gide a principios de 1950. La vigencia de la obra del anciano escritor francés es celebrada y contrastada con la declinación de los últimos trabajos de Valéry, pero sobre todo con la imagen del "escritor puro" (“André Gide” 15). En contraposición, el legado de Gide y su enseñanza para los lectores contemporáneos se cifra en su labor de removedor de conciencias y la fuerte impronta moral de sus textos. Un mes después, Rama publica una nota que puede ser leída como un manifiesto de la generación crítica, en tanto revela algunos de las más urgentes exigencias de los jóvenes hacia la escena cultural uruguaya. En este breve texto de intervención, Rama postula la labor literaria como una actividad imprescindible en la vida del hombre, a pesar de ciertos juicios errados que han cristalizado en el seno de la sociedad moderna: "Ocurre que siempre se ha considerado en menos, con irritante ceguera, la importancia trascendental que para la formación del hombre tiene la experiencia literaria. Ella es la única que puede aproximarse y a veces incluso sustituir la experiencia vital" ("De las muchas" 14). La formación en el campo de las letras aparece aquí jerarquizada frente a otros campos de la cultura y el conocimiento por su capacidad de cimentar cosmovisiones amplias e integrar saberes inconexos, hasta el punto de que una buena y atenta lectura de Cervantes puede, según el crítico, superar en valor y enseñanza a cualquier otra profesión o carrera universitaria. El magisterio de Rodó impulsa la fuerza discursiva de los enunciados y se entronca con un agudo ataque hacia quienes no honran el sacerdocio de la escritura y dilapidan sus esfuerzos en obras leves y poco esforzadas. La exigencia de rigor estético, lucidez intelectual y claridad de conceptos son máximas que se deben asumir para superar una producción literaria todavía marcada por la gratuidad, el facilismo y la mera búsqueda de prestigio social. Las dificultades para sostener la magnitud del desafío en la sociedad uruguaya de la década de 1950 no son desconocidas. Rama las enumera, analiza y desarrolla en el artículo como asunción explícita de las 
funciones rectoras de la crítica literaria, que además de imponer los valores estéticos, debe alertar y orientar a los escritores: "Presentar este panorama, por desalentador que pueda parecer es útil para evitar los engaños [...] Si el ejercicio de las letras es heroico o quijotesco, forzoso será ser leal con las obligaciones que impone" ("De las muchas" 14).

Frente a este tipo de enunciado, cabe volver sobre el testimonio acerca de la época que el propio Rama brinda décadas después en su libro La generación crítica, en función de matizar su insistencia en la irreductible separación entre los esfuerzos de Emir Rodríguez Monegal, cifrados en la difusión de las letras internacionales y la lucha contra la mediocridad de la vida literaria nacional, y los suyos propios, motivados por una necesaria reinserción de las obras en las esferas sociales e históricas (88). La demarcación se demuestra sesgada, por lo menos en este primer período al frente de las páginas literarias de Marcha. Lo mismo ocurre cuando en "La lección intelectual de Marcha", Rama afirma que su antecesor transforma la sección del semanario montevideano en una "sucursal de la revista Sur" (21). Su aserción divide quirúrgica e ideológicamente dos orientaciones que, como se viene registrando, presentan hacia principios de la década de 1950, una clara solidaridad de objetivos y estrategias de intervención. De hecho, los artículos que Rama publica en esta etapa se pueden inscribir sin reservas en el programa crítico que Rodríguez Monegal diagrama por esos años y que luego recoge en su libro La literatura uruguaya de mitad de siglo, en el que sintetiza su apuesta y la de sus colegas según las siguientes palabras: "Lo que caracterizó sobre todo a la generación en su primer momento fue una reacción apasionada y militante contra el quietismo, contra la hipocresía, contra la inautenticidad de la vida literaria uruguaya" (82).

Justamente, la primera confrontación pública entre Ángel Rama y Rodríguez Monegal transcurre hacia 1948 y aparece en tres números consecutivos de Marcha. El motivo inicial es una nota virulenta, escrita por Rama y su compañero Flores Mora, en la que se impugna la última edición del "Concurso de Remuneraciones a la labor literaria" porque las deliberaciones del jurado no han 
sido informadas al público ni justificadas de manera crítica. Con un exaltado tono de denuncia, los dos autores construyen con su intervención un perfil de crítico determinado por la fijación de valores estéticos para la creación literaria y la responsabilidad civil de rendir cuentas ante una comunidad de lectores que demanda su orientación para evitar caer en lecturas nocivas, definidas como "drogas de la peor especie" ("Conducta censurable" 14). Respaldan su postura con una revisión volumen por volumen de todos los libros premiados, lo que funciona como una práctica a contrapelo de la ejercitada por lo que ellos denominan "jueces literarios estatales". La polémica estalla porque uno de los responsables del veredicto es Rodríguez Monegal, quien al siguiente número responde con cierta diplomacia y explica cuestiones relacionadas con el reglamento del concurso, a la vez que defiende sus críticas al sistema de premios, sostenidas anteriormente desde esas mismas páginas literarias de Marcha que él mismo supo dirigir. Pero el tono de la confrontación asciende, ya que Rama y Flores Mora arremeten y lo acusan de deshonestidad intelectual por participar de un certamen al que admite no respetar ("Del Sr."). Así, trasladan la cuestión a un plano moral, que se acentúa en el "Recuento de discrepancias", con el que concluye la polémica tras una segunda carta de Monegal dirigida al director de Marcha. En este último texto, Rama y Flores Mora operan como fiscales morales de las actitudes públicas de su interlocutor. Además de contraargumentar sus opiniones, terminan por augurarle irónicamente su ingreso a la Academia de Letras a causa de sus posiciones complacientes y acomodaticias, "que es a lo que conduce una "objetividad" tan pasiva y cacareada como la suya. Objetividad casi de objeto. Y hasta diríamos, en el caso especial de este jurado, de objeto inútil” (15).

Ciertamente, la polémica sobre el concurso literario forma parte de las numerosas y longevas disputas entre Rama y Rodríguez Monegal, el "conjetural y penoso anecdotario balzaciano" al que se refiere Claudia Gilman (Entre la pluma 390). El enfrentamiento responde en gran medida a una lógica de oposiciones sobre las que ambos se montan desde entonces, descreídos del valor de la obra crítica del otro, pero también recelosos de sus posiciones intelectuales, filiaciones políticas y 
proyecciones continentales. El sentido de revisar esta primera confrontación reside en identificar cómo el compromiso sartreano se empieza a imponer como cifra de la praxis de Rama, pero circunscrito en esta instancia a problemáticas y tópicos privilegiados por la "ciudad letrada" montevideana. A partir de él se fija la importancia del imperativo público, la sanción moral y la desconfianza ante la objetividad. Estos elementos conviven por entonces en su discurso con modalidades menos combativas y más vinculadas con las propias inspiraciones, objetivos y estrategias de Emir Rodríguez Monegal. La misma atención volcada hacia el sistema de concursos comprueba la premisa, en consonancia con otros temas específicos (como la actividad editorial americana o las revistas culturales uruguayas), sobre los cuales Rama escribe de forma recurrente, colocándolos como tópicos privilegiados de las páginas literarias de Marcha y de su propia praxis crítica, de esos años en adelante.

Para concluir con la indagación alrededor de la primera experiencia del joven crítico en el semanario, es necesario detenerse en los últimos dos artículos que escribe hacia abril de 1948. En uno de ellos vuelve a expresar su interés por la literatura española y su admiración por la obra narrativa de Benito Pérez Galdós. Lo hace a través de una argumentación que inicia un largo período de reflexión sobre el género novelesco, hasta entonces desplazado de su lectura por la poesía, el teatro o el ensayo. El texto parte del examen de la situación de la novela contemporánea, a la que encuentra dominada por un desenfrenado afán de experimentación. Situado en ese punto de la historia literaria, Rama traza una suerte de dialéctica según la cual la novela alcanza una etapa clásica de producción en el siglo XIX, en la que son escritas las obras cumbres del realismo decimonónico (Balzac, Tolstoi, Dickens, Galdós), para enseguida caer en un movimiento de puesta en duda de las tradiciones heredadas y la consiguiente apertura de múltiples e inusitadas sendas de análisis, crítica, análisis y creación. Pero la extenuación del afán vanguardista, del cual participa incluso la narrativa del existencialismo, lleva a un estado de nostalgia que añora las novelas de los grandes maestros, por lo que estas tienen de representación racional e integradora. El panorama actual de la 
CATEDRAL TomadA: Revista de crítica literaria latinoamericana / Journal of Latin American Literary Criticism Los primeros ensayos de Ángel Rama: inicios montevideanos de una crítica latinoamericana.

novela extraña, según Rama, "una visión totalizadora y verdadera, contrapuesta a la debilidad y al nerviosismo femenil de los novelistas de este siglo" ("Magisterio" 14). Es en ese marco que se levanta a Galdós como modelo: la obra del escritor español, capaz de abordar colosales dramas históricos desde una multitud de personajes ficticios que recrean con veracidad el significado de una época histórica, funciona como dirección válida para la creación de los nuevos escritores.

La argumentación, de fuerte raigambre humanista y conservadora en lo que hace al paradigma estético elegido, se matiza en el artículo siguiente, en el que Rama vuelve a reflexionar sobre el rumbo de la novela contemporánea. En este caso, el ejemplo es inesperado. Luego de revisar la idea de una crisis del género en el siglo XX, se afirma que la situación actual de la novela, interpretada por muchos intelectuales como un lánguido ocaso, se plantea en términos de una transformación radical. La escala se reduce y se dirige a la escena literaria argentina, sobre la cual Rama se manifiesta tan contrario a la producción del grupo Sur por su abandono de "la gran tradición europea" como entusiasta de la obra de Roberto Arlt, al que califica como "el último novelista argentino" ("Nuestra historia" 14) a causa de su renuncia al alambicamiento instituido por Borges y sus seguidores. ${ }^{5}$

El razonamiento de Rama sobre la novela en estos años de formación exhibe una notable desconfianza ante la innovación formal, encabalgada a una apuesta concisa por el realismo más clásico, lo que subraya la inflexión humanista de sus lecturas y análisis, impregnadas por el arielismo estético uruguayo y las cuestiones planteadas por algunas derivaciones de la estilística española. Su discurso se muestra ajeno a otras conceptualizaciones y aportes del pensamiento moderno, como los ligados a la sociología de la cultura o la estética marxista. El único referente teórico que campea en estas páginas es el infaltable maestro José Bergamín, bajo cuya prédica Rama retoma y adhiere a la metáfora de Stendhal de la novela como espejo que se pasea a lo largo del camino. El crítico insta así a los

\footnotetext{
${ }^{5}$ Vale la pena destacar que Rama interpreta de este modo la narrativa de Arlt varios años antes de su definitiva revisión del otro lado del Río de la Plata, por parte de los jóvenes críticos reunidos en la revista porteña Contorno.
} 
escritores a volverse sobre la historia uruguaya y a representar sus temas, episodios y procesos más célebres sin caer en el pintoresquismo costumbrista, pero mucho menos en la gratuidad y desorientación del experimentalismo contemporáneo.

\section{Rama en Asir y Entregas de La Licorne: el otro y el mismo}

Luego de su paso por Marcha, Rama divide su tiempo en diferentes trabajos. A su cargo en la Biblioteca Nacional le agrega una fecunda tarea en la Biblioteca Artigas. Durante los próximos años, muchos de los volúmenes publicados en la Colección de Clásicos Uruguayos cuentan con su colaboración en el armado y edición. En 1950 se fija otro hito en su trayectoria como intelectual: junto a Carlos Maggi funda Ediciones Fábula, el emprendimiento que marca sus inicios en la labor editorial. El sello publica los primeros libros de Rama: un ensayo sobre el artista y escritor uruguayo Pedro Figari y la novela ¡Oh, sombra puritana!

La edición es una faceta de su vida que se torna fundamental para comprender su manera de concebir las tareas de la crítica literaria y aún para imbricar sus textos y ensayos en una esfera práctica que excede con creces los límites del discurso escrito. En este sentido, la propuesta de Gonzalo Aguilar de entender a Rama como uno de los "intelectuales públicos" latinoamericanos de la segunda mitad del siglo XX es correcta incluso desde una perspectiva no advertida por el autor ("Los intelectuales"). Para sujetos heterodoxos como el uruguayo, ser "intelectual" y ser "público" implica una gama de intervenciones mucho más amplia que el estudio de los textos, la participación en polémicas literarias, la creación de términos teóricos o la revisión de metodologías de investigación. Asumir el rol de crítico en el seno de una sociedad dependiente es también, según 
CATEDRAL TomadA: Revista de crítica literaria latinoamericana / Journal of Latin American Literary Criticism Los primeros ensayos de Ángel Rama: inicios montevideanos de una crítica latinoamericana.

la opinión y la propia vida de Rama, traducir, editar, gestionar, enseñar, difundir, religar. ${ }^{6}$

Además de estos trabajos, Ángel Rama inicia hacia 1952 su carrera como profesor en distintos liceos montevideanos, en los que se desempeña hasta 1966, cuando finalmente se incorpora al plantel docente de la Facultad de Ciencias y Educación. La acumulación de tareas explica en parte la palpable merma en la cantidad de artículos publicados sobre literatura que se registra entre 1950 y 1957 , período en el cual las páginas literarias de Marcha vuelven a ser dirigidas por Emir Rodríguez Monegal. Durante esos años, Rama destina parte de sus esfuerzos en participar como columnista de ocasión en las secciones culturales de algunos diarios y revistas uruguayos y luego pasa a desarrollar una sostenida tarea como crítico teatral en Acción, el periódico del Partido Colorado, que se extiende entre 1957 y 1960. Al interior de ese hiato marcado entre el fin de su colaboración en Marcha y el inicio de su dedicación al teatro, se destacan dos series de textos en las que Rama avanza sobre temas literarios. Lo hace en dos revistas literarias muy diferentes: Asir y Entregas de La Licorne. Con la revisión de estos ensayos concluye el presente trabajo y su intento por demostrar cómo la consideración de anclajes y perspectivas situadas al inicio de carrera de Rama rediseñan un nuevo mapa de tensiones, continuidades y desplazamientos que obliga a repensar etiquetas y periodizaciones establecidas acerca de sus aportes a la crítica literaria latinoamericana moderna.

Asir es una las revistas uruguayas más importantes de la década de 1950. Publicada entre 1948 y 1959, nuclea a un grupo de escritores de la ciudad de Mercedes que se identifican con los intereses del interior del país y que participan, desde esa precisa instancia de enunciación, de la discusión general sobre la cultura

${ }^{6}$ Es por esta razón que son tan valiosas las investigaciones que van más allá de la interpretación de los ensayos de Rama y apuestan a explorar sus tentativas culturales desde su más amplia diversidad. Sobre la actividad editorial de Rama, por ejemplo, se destacan los trabajos de Rocca (“Ángel Rama, editor”) en torno a la Enciclopedia Uruguaya y, especialmente, el de Alejandra Torres Torres acerca de las editoriales uruguayas Alfa y Arca; esta última, una de las más fecundas iniciativas de Rama en este campo (Lectura y sociedad). 
nacional que atraviesa esos años. Los intelectuales vinculados con Asir representan una alternativa a las orientaciones más urbanas y cosmopolitas de la escena montevideana e integran una de las facciones en disputa acerca del rumbo a seguir por el país en un contexto de crisis (Espeche 65). La única ocasión en la que Ángel Rama participa de la publicación es en el tomo especial que la revista le dedica al centenario de José Martí en 1953. Lo hace por partida doble, con un díptico que traza una interpretación general de la poesía del poeta cubano Martí y luego se detiene en el análisis detallado de "La niña de Guatemala". En conjunto, conforman el primer acercamiento del crítico a la obra de un intelectual que hasta sus últimos años aparece en un lugar privilegiado de su discurso, tal como lo expresa el mismo Rama en la última entrevista que brinda (Díaz-Caballero 338) o la más reciente compilación de Biblioteca Ayacucho que recoge sus ensayos martianos más clásicos (Martí. Modernidad).

La lectura de "Luz y sombra en la poesía de Martí", el artículo más abarcador de los dos, se inicia con una cita del español Federico de Onís que formula la hipótesis general que sigue el ensayo: pensar al cubano como el escritor que logra percibir como nadie las posibilidades y desafíos que la modernidad rasante impone al mundo y a las letras. Luego de organizar prolijamente la bibliografía del poeta e identificar los temas literarios y coyunturas históricas esenciales de su trayectoria, Rama postula que gran parte de su potencia lírica reside en una tensión estructural provocada por la superposición de dos "hemisferios", modalidades artísticas que expresan la configuración moral del poeta cubano ("Luz y sombra" 49). Uno de ellos es denominado por Rama como "canto roto" y manifiesta, a través de los particulares usos de la versificación y los recursos poéticos, el desgarramiento existencial que Martí experimenta ante su vida personal y los eventos históricos funestos. El otro hemisferio es bautizado como "canto pleno" y refiere a los estallidos sentimentales y momentos de iluminación de su poesía, en los cuales el yo lírico alcanza una fusión armoniosa entre lenguaje y materia. El juego entre los dos polos es el centro de un corpus que replica hacia su seno las fuerzas contradictorias de una modernidad que todo lo mueve y que se 
CATEDRAL TomadA: Revista de crítica literaria latinoamericana / Journal of Latin American Literary Criticism Los primeros ensayos de Ángel Rama: inicios montevideanos de una crítica latinoamericana.

revela como el primer bosquejo de un modelo de interpretación crítica sobre el que Rama vuelve en los últimos trabajos de su vida. Como es posible comprobar, esta operación crítica que reconstruye tensiones polares al interior de un corpus literario y que resalta la mutua interacción entre formas literarias y respuestas culturales ante el desafío modernista, es análoga a la desplegada sobre la obra de Arguedas y la historia literaria latinoamericana en algunos de los ensayos que Rama publica ya hacia la década de 1980 ("La tecnificación”, Transculturación). En el otro texto publicado por Asir se percibe una estrategia de lectura similar, pero limitada al análisis de "La niña de Guatemala", el poema de Martí publicado en Versos Sencillos. La argumentación de Rama se inicia con el examen de los puntos de contacto entre el texto y la biografía del cubano, pero prontamente se abandona la inflexión biograficista más llana para volcarse a un estudio minucioso de los versos, que avanza guiado por una teoría de la conciliación armónica de los pares opuestos (“Análisis"). Nuevamente, la poesía se coloca como una actividad trascendente y utópica y el poeta como un genio sensible y lúcido que logra una síntesis lírica donde en apariencia solo reina el caos y el desconsuelo. ${ }^{7}$

José Martí vuelve a ser objeto de la crítica de Rama, quien publica hacia noviembre de 1953 otro ensayo sobre el cubano, pero esta vez en las páginas de Entregas de La Licorne, la publicación fundada por la poeta uruguaya Susana Soca en París hacia 1947, cuya segunda época se imprime en francés y en español desde 1953 en Montevideo (Barite y Ceretta 35). La inesperada presencia de Ángel Rama en una empresa tan refinada y exquisita como ésta, que dedica homenajes a figuras como Paul Éluard o María Eugenia Vaz Ferreira y publica textos de Alberti, Pasternak, Borges, Bioy Casares, Caillois o Reyes, se intensifica al comprobar que el joven crítico se desempeña allí como secretario de redacción hasta 1956. Al interior de sus textos, la inflexión académica e idealista de su escritura se exaspera. Esta deriva se empieza a percibir en "Martí, poeta visionario", un artículo en el que

\footnotetext{
${ }^{7}$ Con un lenguaje más técnico y un bagaje teórico mucho más sofisticado, la proposición central e incluso ciertos visos metodológicos de esta interpretación de Ángel Rama sobre la poesía de Martí reaparece sorpresivamente (o no tanto) en el ensayo "Indagación de la ideología en la poesía. Los dípticos seriados de Versos sencillos".
} 
Rama desarrolla y profundiza la lectura ya propuesta en los artículos de Asir. La comparación entre las dos intervenciones revela significativas marcas del pasaje entre una instancia de enunciación y otra, como, por ejemplo, el mayor nivel de elaboración de su prosa ensayística (que se puebla de metáforas y oraciones subordinadas), la creciente inclusión de citas cultas (Baudelaire, Santa Teresa) y sobre todo, la marcada perspectiva esteticista, que prefiere ensalzar el lirismo y el carácter epistemológico de la poesía de Martí en desmedro de otras cuestiones como el desgarramiento, la modernidad o la militancia política. El intelectual cubano aparece vaciado de tensiones: las múltiples facetas de su praxis se subsumen en el exclusivo legado lírico. Incluso, Rama afirma que ya existe un consenso sobre este juicio, "como decir que la obra más persistente que cumplió fue la de perfeccionar esta cualidad superior de lo humano con que se vio señalado desde su adolescencia: ser poeta" ("Martí" 157).

Tal como se leyó en algunos textos de Clinamen y Marcha, aquí también el discurso de Rama discurre sobre la entronización del escritor como sujeto social privilegiado, garante de valores culturales y responsable de la más celebrada obra civilizatoria. En 1954 otros dos artículos de Entregas de La Licorne prolongan esta dirección. El primero está dedicado a la poeta uruguaya María Eugenia Vaz Ferreira (1954) y se constituye como un ejemplo extremo de este "otro" Ángel Rama que descubre la pesquisa de su archivo bibliográfico. La referencia a la autora es tan cercana ("María Eugenia", la llama repetidas veces) que todo el ensayo adquiere la forma de una encomiástica charla entre lectores convencidos de la excelencia de su obra. En la primera página, el crítico admite que todo artista "nos revela íntegramente su alma en la elección de sus temas"; en la segunda, se agrega que la creación lírica tiene un origen involuntario e impuesto al poeta por los dictámenes del alma. Rama lee la obra de Vaz Ferreira como el cumplimiento de un destino poético que sufre ante la consecuencia última de esta lealtad lírica: la marginación definitiva de la sociedad y de la historia. 
CATEDRAL Tomada: Revista de crítica literaria latinoamericana / Journal of Latin American Literary Criticism Los primeros ensayos de Ángel Rama: inicios montevideanos de una crítica latinoamericana.

En ciertos fragmentos, el exagerado sesgo idealista sugiere incluso un error de autoría o un plagio. A cualquier especialista en estudios literarios latinoamericanos le costará mucho relacionar el nombre de Ángel Rama con frases como la siguiente:

En el poeta la libertad le permite entablar el diálogo con su destino del que surge su poesía, porque es ella siempre un diálogo, más que con su tiempo como quiso Machado, con una eternidad supraindividual, suprahumana, que desciende amorosamente, y así lo entrevió Blake, a las cosas temporales. ("Espiritualidad" 60) ${ }^{8}$

Aunque cualquier extrañeza del lector ante el fragmento esté plenamente justificada, no hay elementos bibliográficos para suponer que no es Ángel Rama quien en efecto suscribe el enunciado, que es solo una muestra parcial de la entonación general de su discurso en Entregas de La Licorne. Si esto se debe a una voluntariosa adecuación al tono dominante en la revista de Susana Soca, cabe entrever un gesto por lo menos exagerado.

Por lo pronto, un último ejemplo lleva el enfoque idealista a un campo literario por entonces casi inexplorado. En el texto titulado "Temas tradicionales", el crítico ensaya sus primeras reflexiones sobre la literatura del continente americano, guiado en principio por los trabajos de Luis Alberto Sánchez y Mariano Picón Salas y a través de una reflexión totalizadora y ya plenamente reconocible. En ella, reconoce al Barroco de Indias como la primera expresión de la sensibilidad americana, que inaugura un proceso de integración literaria entre el Viejo y el Nuevo Mundo a través de la desmesura bárbara compartida por los versos de Góngora y Sor Juana, por ejemplo.

${ }^{8}$ Cfr. las posiciones del propio Rama en la polémica con Mario Vargas Llosa de la década de 1970. En el fragmento citado resuena con un eco todavía más romántico la idea del novelista peruano acerca del escritor y sus demonios que Rama defenestra por idealista y arcaica (García Márquez). 
Sin embargo, en estas páginas el latinoamericanismo de Rama no es el que caracteriza sus obras más clásicas, sino uno completamente distinto, al que resultaría más correcto denominar "hispanoamericanismo", habida cuenta de que la ecuación central que ordena estas hipótesis es la igualación plena y sin fisuras entre literatura y lengua, tal como se colige de frases como la que sigue: "No creo que pueda entenderse una literatura sino como una lengua, un habla que se organiza en estructuras estéticas, reconociendo a esa lengua, con frase orteguiana, un espíritu animador" ("Temas" 141). Rama no se refiere a cualquier lengua, sino a una: la española, lo que supone postular que la tradición literaria de la América hispánica se halla completamente incorporada en la historia de las letras peninsulares, cuya centralidad ningún tipo de influencia contemporánea debe desdibujar, a riesgo de cortar el fértil y secular diálogo interoceánico. La hispanofilia inicial del joven Rama adquiere aquí una nueva formulación, cuando señala que descree de "una invención poética nueva que no cuente con la vieja y actual experiencia poética peninsular, en la que algún crítico ha visto la segunda edad de oro de la poesía española" (141). Así, desde esta precisa conceptualización sobre la lengua y las letras, cuyo sentido colonialista es evidente, su primer ensayo sobre la literatura latinoamericana imagina un proyecto de integración cultural despojado del carácter militante, emancipador y hasta revolucionario que caracterizará su discurso e intervenciones de las próximas décadas.

Un abismo ideológico, teórico y crítico parece entonces separar la futura figura del gran "intelectual público" latinoamericano de los esfuerzos de este joven Rama montevideano, que intenta sobre todo destacarse entre el plantel de escritores y críticos que dominan la escena cultural uruguaya. El rastreo de sus primeros trabajos permite reconstruir un iniciático perfil profesional volcado hacia literaturas metropolitanas, pautado por el imperativo modernizador e impregnado de un humanismo a ultranza, que por momentos declina hacia el idealismo estético y por otros hacia el enjuiciamiento existencialista. Desde esa particular configuración, el discurso crítico de Rama aparece signado por la búsqueda de valores trascendentes en las obras literarias, posturas consecuentes en el campo intelectual uruguayo y 
CATEDRAL Tomada: Revista de crítica literaria latinoamericana / Journal of Latin American Literary Criticism Los primeros ensayos de Ángel Rama: inicios montevideanos de una crítica latinoamericana.

guías de pensamiento y conducta en el orbe francés y español. América Latina se mira desde lejos y a través de la mediación de referentes clásicos y legitimados, mientras que la novela se coloca como un género contemporáneo cuyo valor es puesto en duda. La reflexión sobre este tema presenta distintos matices, pero es posible reconstruir una posición al menos dubitativa sobre sus capacidades de representación histórica y realización estética.

Si se tiene en cuenta la distancia temporal que media entre los últimos textos que Rama escribe para Entrega de La Licorne y los primeros artículos que publica en su regreso definitivo a las páginas literarias de Marcha, se comprueba que han pasados apenas cuatro años entre una y otra experiencia. Esto explica por qué, incluso ya inserto en el semanario de orientación anti imperialista, la sección dirigida por Ángel Rama continúa durante un tiempo todavía la orientación marcada por Emir Rodríguez Monegal y otros integrantes de la generación crítica. Todos participan de las mismas aspiraciones y apenas difieren en algunos gustos y afinidades. Por lo tanto, hay que esperar el compromiso de Rama con la Revolución Cubana y el impacto de su llamado latinoamericanista para empezar a reconocer en sus textos las marcas que harán de él aquel intelectual público que defiende y promociona la "nueva novela" latinoamericana y se vuelca a conectar esfuerzos de críticos y escritores en pos de una integración del subcontinente a través de la literatura y el arte.

Una biografía nunca es lineal y las trayectorias intelectuales no se pueden aplanar con meras ideas de evolución o maduración, por lo que resta señalar, como conclusión de este trabajo, que las modulaciones analizadas del joven Rama no pueden ser pensadas como un anecdotario fútil o un insignificante trabajo de archivo. Muchas de las hipótesis críticas y metodologías de trabajo que luego él elabora sobre la narrativa y el pensamiento latinoamericano presentan rasgos y matices ya desarrollados en estos años y a través de estos textos tempranos. Muchas aporías que los más recientes estudios han encontrado en algunas de sus acuñaciones teóricas pueden ser mejor entendidas a partir de la constatación del carácter heterogéneo de su praxis y de un itinerario intelectual que, como se vio, 
atraviesa distintas etapas. Las mismas no siguen una lógica lineal, conclusiva ni teleológica ni tampoco son canceladas en su totalidad, sino que se imantan con sus proposiciones y perspectivas unas a otras. Así, entender estos trabajos montevideanos como "precursores", "anticipaciones" o "gérmenes" de algo que recién madura más adelante es una operación inconducente, que aplana los sentidos que se intentaron resaltar. Más ajustado y más productivo es pensar esta parte del discurso crítico de Ángel Rama como los primeros ensayos de quien busca ingresar a la esfera literaria nacional a través de una audaz tentativa intelectual, bien imbricada en el medio y comprometida con sus mayores desafíos. Los pasos siguientes, que incluyen el salto al plano continental, la afinación del arsenal interpretativo y la ejecución de una extensa agenda de integración latinoamericana, serán dados en adelante por Rama a partir de esta primera matriz de lecturas e intervenciones, cuyos ejes se desplazan, pero no desaparecen. Lejos de ser elementos caducos de una temprana primera etapa, se presentan en su praxis y pensamiento como perspectivas remanentes que interactúan en sus intervenciones futuras y las dotan de una naturaleza compleja, original y, muchas veces, también problemática. 
CATEdral TomadA: Revista de crítica literaria latinoamericana / Journal of Latin American Literary Criticism Los primeros ensayos de Ángel Rama: inicios montevideanos de una crítica latinoamericana.

\section{Bibliografía}

Aguilar, Gonzalo. "Los intelectuales de la literatura: cambio social y narrativas de identidad". Historia de los intelectuales en América Latina. Tomo II. Edición de Carlos Altamirano, pp. 685-711. Buenos Aires, Katz, 2010.

Barite, Mario y María Gladys Ceretta. Guía de revistas culturales uruguayas (1895-1985). Montevideo, El galeón, 1989.

Blixen, Carina y Álvaro Barros-Lémez. Cronología y bibliografía de Ángel Rama. Montevideo, Fundación Ángel Rama, 1986.

Barros-Lémez, Álvaro. “Ángel Rama narrador”. Hispamérica no 39, 1984, 49-54.

Díaz-Caballero. “Ángel Rama o la crítica de la transculturación (última entrevista)". Ángel Rama y los estudios latinoamericanos. Compilación de Mabel Moraña, pp 325-343. Pittsburgh, Instituto Internacional de Literatura Iberoamericana, 1997.

Espeche, Ximena. "De una isla a otra: intelectuales uruguayos y América Latina como problema a mediados del siglo XX (1952-1962)". Anclajes no. 14, 2010, pp. 51-72.

Gilman, Claudia "Enredos y desenredos de Rama y Monegal”. Nuevo texto crítico no. 24-25, 2012, pp. 47-48.

-------. Entre la pluma y el fusil. Debates y dilemas del escritor revolucionario en América Latina. Buenos Aires, Siglo Veintiuno, 2012.

Green, Julien. “Cristina”. Trad. Ángel Rama. Clinamen no.1, 1947, pp. 33-40.

Moraña, Mabel. "La narrativa de Ángel Rama". Memorias de la generación fantasma, pp. 201-211. Monte Sexto, 1988.

Rama, Ángel. "Sobre la composición de El gaucho Martín Fierro". Clinamen, no. 2, 1947, pp. 31-44.

------. “La historia y la novela, por Carlos Rama”. Seud. Antonio Facal. Clinamen, no. 2, 1947, pp. 62-63. 
CATEDRAL TOMADA: Revista literaria latinoamericana / Journal of Latin American Literary Criticism Facundo Gomez

------- “El preso". Clinamen, no. 4, 1948, pp. 9-13.

------. "Temporada de teatro Nacional". Seud. Antonio Facal. Clinamen, no. 4, 1948, pp. 39-40.

------. “La Fontaine y sus fábulas” por Carlos Vossler”. Clinamen, no. 4, 1948, pp. 51-52.

------. “Generación va y generación viene”. Clinamen, no. 5, 1948, pp. 52-53.

------. “¿Obras completas de Antonio Machado?”. Marcha, no. 516, 1950, pp. 15.

------. “Albert Camus”. Marcha, no. 500, 1949, pp. 15.

-------. “Conducta censurable de un jurado”. Marcha, no. 505, 1949, pp. 14-15.

-------. “Rafael Alberti leerá La Gallarda”. Marcha, no. 506, 1949, pp. 15.

------. “Del Sr. E. Rodríguez Monegal”. Marcha no. 506, 1949, pp. 15.

------. "Recuento de discrepancias". Marcha, no. 507, 1949, pp. 15.

------. “Algunas conferencias del año”. Marcha, no. 510, segunda sección, 1950, pp. 5.

------. “Crisis editorial en América Latina”. Marcha, no. 510, segunda sección, 1950 , pp. 5.

-------. “Castelao”. Marcha, no. 512, 1950, pp. 15.

-------. “Inéditos de Miguel Hernández”. Marcha, no. 513, 1950, pp. 14-15.

------. “Los escritores franceses y la política”. Marcha, no. 514, 1950, pp. 15.

------. “André Gide”. Marcha, no. 515, 1950, pp. 15.

------. "De las muchas vocaciones y los pocos escritores". Marcha, no. 517, 1950, pp. 14.

-------. “Magisterio de Galdós". Marcha, no. 524, 1950, pp. 14-15.

------. "Nuestra historia como materia novelable". Marcha, no. 529, 1950, pp. 1415.

-------. “La construcción de una literatura”. Marcha no. 1041, 1960, pp. 24-26.

-------. “Luz y sombra en la poesía de Martí”. Asir, no. 30-31, 1953 pp. 43-54. 
CATEDRAL TOMADA: Revista de crítica literaria latinoamericana / Journal of Latin American Literary Criticism Los primeros ensayos de Ángel Rama: inicios montevideanos de una crítica latinoamericana.

-------. “Análisis de `La niña de Guatemala'”. Asir, no. 30-31, 1953 pp. 66-78.

-------. "Martí, poeta visionario". Entregas de La Licorne, no. 1, 1953 pp. 157160.

-------. "Espiritualidad creadora: la obra de María Eugenia Vaz Ferreira".

Entregas de La Licorne, no. 3, 1954, pp. 35-66.

------. “Temas tradicionales". Entregas de la Licorne no. 5-6, 1955, pp. 135-144.

-------. La generación crítica. Montevideo, Arca, 1972.

------.. Los gauchipolíticos rioplatenses. Literatura y sociedad. Buenos Aires, Calicanto, 1976.

------- “Indagación de la ideología en la poesía (Los dípticos seriados de Versos sencillos)". Revista Iberoamericana 112, 1980, pp. 353-400.

------. “La tecnificación narrativa". En La novela en América Latina. Panoramas 1920-1980, 1981, pp. 321-392. Santiago de Chile, Universidad Alberto Hurtado, 2008.

-------. Terra sem mapa. Trad. y prólogo de Roseli Barros Cunha. São Paulo, Grua. 2008.

-------. "La lección intelectual de Marcha". Cuadernos de Marcha, segunda época, no. 19, 1982, pp. 19-25.

-------. Transculturación narrativa en América Latina. El Andariego, 2007.

-------. Martí. Modernidad y latinoamericanismo. Compilación de Julio Ramos y María Fernanda Pampín, estudio introductorio de María Fernanda Pampín. Caracas, Biblioteca Ayacucho, 2015.

Rama, Ángel y Mario Vargas Llosa. García Márquez y la problemática de la novela. Corregidor, 1973.

Rocca, Pablo. 35 años en Marcha (Crítica y literatura en el semanario y en el Uruguay 139-1974). Montevideo, División Cultura-Intendencia Municipal, 1992. 
------. "Las revistas: invención y construcción de lectores (Un dilema a dos orillas, 1947, 1962)". Revistas culturales del Río de la Plata. Diálogos y tensiones (1945-1960). Editado por Pablo Rocca, pp. 13-56. Montevideo, Universidad de la República, 2012.

-. El 45. Entrevistas/Testimonio. Montevideo, Ediciones Banda Oriental, 2004. Ángel Rama, Emir Rodríguez Monegal y el Brasil: Dos caras de un proyecto latinoamericano. Montevideo, Ediciones de la Banda Oriental, 2006.

. "Ángel Rama, editor (de la literatura a la cultura: "Enciclopedia uruguaya" y sus derivaciones)". Coloquio Argentino de Estudios sobre el Libro y la Edición. Octubre-noviembre, 2012, coloquiolibroyedicion.fahce.unlp.edu.ar/actas/Rocca.pdf/view.

Rodríguez Monegal, Emir. La literatura uruguaya de mitad de siglo. Montevideo, Alfa, 1966.

Ruffinelli, Jorge. “Ángel Rama Marcha, y la crítica literaria latinoamericana en los 60s”. Nuevo Texto Crítico, no. 7, 1994, pp. 49-59.

Torres Torres, Alejandra. Lectura y sociedad en los sesenta: a propósito de Alfa y Arca. Montevideo, Yaugurú, 2012.

Zanetti, Susana. “Ángel Rama y la construcción de una literatura latinoamericana”. Revista Iberoamericana no. 160, 1992, pp. 919-932. 